\title{
Paraconsistent artificial neural networks and Alzheimer disease A preliminary study
}

\author{
Jair Minoro Abe ${ }^{1}$, Helder Frederico da Silva Lopes ${ }^{2}$, Renato Anghinah ${ }^{3}$
}

\begin{abstract}
EEG visual analysis has proved useful in aiding AD diagnosis, being indicated in some clinical protocols. However, such analysis is subject to the inherent imprecision of equipment, patient movements, electric registers, and individual variability of physician visual analysis. Objectives: To employ the Paraconsistent Artificial Neural Network to ascertain how to determine the degree of certainty of probable dementia diagnosis. Methods: Ten EEG records from patients with probable Alzheimer disease and ten controls were obtained during the awake state at rest. An EEG background between $8 \mathrm{~Hz}$ and $12 \mathrm{~Hz}$ was considered the normal pattern for patients, allowing a variance of $0.5 \mathrm{~Hz}$. Results: The PANN was capable of accurately recognizing waves belonging to Alpha band with favorable evidence of 0.30 and contrary evidence of 0.19 , while for waves not belonging to the Alpha pattern, an average favorable evidence of 0.19 and contrary evidence of 0.32 was obtained, indicating that PANN was efficient in recognizing Alpha waves in $80 \%$ of the cases evaluated in this study. Artificial Neural Networks - ANN - are well suited to tackle problems such as prediction and pattern recognition. The aim of this work was to recognize predetermined EEG patterns by using a new class of ANN, namely the Paraconsistent Artificial Neural Network - PANN, which is capable of handling uncertain, inconsistent and paracomplete information. An architecture is presented to serve as an auxiliary method in diagnosing Alzheimer disease. Conclusions: We believe the results show PANN to be a promising tool to handle EEG analysis, bearing in mind two considerations: the growing interest of experts in visual analysis of EEG, and the ability of PANN to deal directly with imprecise, inconsistent, and paracomplete data, thereby providing a valuable quantitative analysis.
\end{abstract}

Key words: EEG, Alzheimer disease, pattern recognition, artificial neural network, paraconsistent logic.

\section{Rede neural artificial paraconsistente e doença de Alzheimer: estudo preliminar}

Resumo - A análise visual de EEG tem se mostrado útil na ajuda de diagnóstico de DA, sendo indicado em alguns protocolos clínicos. Porém, tal análise está sujeita à imprecisão inerente de equipamentos, movimentos do paciente, registros elétricos e variação individual da análise visual do médico. Objetivos: Utilizar a Rede Neural Artificial Paraconsistente para saber como determinar um grau de certeza no diagnóstico da doença de Alzheimer provável. Métodos: Dez pacientes com doença de Alzheimer provável e 10 controles foram submetidos ao registro de exames de EEG durante a vigília em repouso. Considerou-se como padrão normal de um paciente, a atividade de base entre $8,0 \mathrm{~Hz}$ a $12,0 \mathrm{~Hz}$, permitindo uma variação de $0.5 \mathrm{~Hz}$. Resultados: A RNAP foi capaz de reconhecer ondas que pertencem à banda Alfa como banda Alfa com evidência favorável de 0.30 e evidência contrária de 0.19 , enquanto ondas não pertencentes ao padrão Alfa, foi obtido uma evidência favorável média de 0.19 e evidência contrária de 0.32 , mostrando que a RNAP foi eficiente para reconhecer ondas Alfa, o que leva a uma concordância com o diagnóstico clínico de $80 \%$. Conclusões: RNAP pode ser ferramenta promissora para manipular análise de EEG, tendo em mente ambas considerações: o interesse crescente de especialistas em análise visual de EEG e a capacidade da RNAP tratar diretamente dados imprecisos, inconsistentes e paracompletos, fornecendo uma interessante análise quantitativa.

Palavras-chave: EEG, doença de Alzheimer, rede neural artificial, reconhecimento de padrões, lógica paraconsistente.

${ }^{1}$ Institute For Advanced Studies - University of São Paulo, Brazil. ${ }^{2}$ Graduate student of M edical School of University of São Paulo - Brazil. ${ }^{3}$ Reference Center of Behavioral Disturbances and Dementia (CEREDIC) of the Medical School of University of São Paulo, Brazil.

Jair Minoro Abe - Av. Prof. Luciano Gualberto / Travessa J, 374 / Térreo / Cidade Universitária - 05508-900 São Paulo SP - Brazil. 
Several studies on behavioral and cognitive neurology have been conducted to characterize dementias by means of biological and functional markers aimed at understanding the evolution of Alzheimer disease (AD), following its progression, as well as leading toward better diagnostic criteria for early detection of cognitive impairment. ${ }^{1,2}$

At present, there is no method able to determine a definitive diagnosis of dementia, where a combination of tests is needed to reach a probable diagnosis. ${ }^{3}$

The electroencephalogram (EEG) is a record of brain electrical signal activity, providing a space-time representation of synchronic postsynaptic potentials. The main generating sources of these electrical fields are most likely perpendicular in relation to the cortical surface, such as in the cortical pyramidal neurons. ${ }^{4}$ During the relaxed awake state, normal EEG in adults is predominantly composed by the alpha band frequency, which is generated by interactions of the slum-cortical cortical and thalamocortical systems. ${ }^{5,6}$

Several studies have shown that EEG visual analysis is useful in aiding $\mathrm{AD}$ diagnosis, being indicated in some clinical protocols. ${ }^{3,4}$

The most common finding in EEG visual analysis is the slowing background of the brain electrical activity compounds regarding delta and theta rhythms, and the decreasing or absence of the alpha rhythm. However, these findings are more common in moderate and advanced stages of $\mathrm{AD} .^{3}$

The majority of theories and techniques available for quantitative EEG analysis are based on classical logic and so cannot adequately such sets of information, at least directly. Although several theories have been developed in order to overcome these limitations, e.g. Fuzzy set theory, Rough theory, non-monotonic reasoning, among others, they cannot deal with inconsistencies and paracompleteness. Thus, we need a new kind of logic to deal with uncertain, inconsistent and paracomplete data. ${ }^{7,8}$

The Artificial Neural Network - ANN - can be described as a computational system consisting of a set of highly interconnected processing elements, called artificial neurons, which process information as a response to external stimuli. An artificial neuron is a simplistic representation that emulates the signal integration and threshold firing behavior of biological neurons by means of mathematical structures. Like their biological counterparts, artificial neurons are bound together by connections that determine the flow of information between peer neurons. Stimuli are transmitted from one processing element to another via synapses or interconnections, which can be excitatory or inhibitory. ${ }^{9,10}$

The advantage of neural networks over conventional programming lies in their ability to solve problems that do not have an algorithmic solution or where the available solution is too complex to be found. ${ }^{11}$ Neural networks are well suited to tackle problems that people are good at solving, such as prediction and pattern recognition. Neural networks have been applied within the medical domain for clinical diagnosis, ${ }^{15}$ image analysis and interpretation, ${ }^{12,13}$ signal analysis and interpretation, and drug development. ${ }^{14}$

Therefore, ANN constitutes an interesting tool for EEG qualitative analysis. On the other hand, in EEG analysis we are faced with imprecise, inconsistent and paracomplete data. In order to manipulate this information directly, some interesting theories have been proposed recently: Fuzzy sets, Rough sets, among others.

In this study we employed a new kind of ANN based on Paraconsistent Annotated Evidential Logic E $\tau$, which is capable of manipulating imprecise, inconsistent and paracomplete data in order to make a first study of the recognition of EEG standards with the aim of using this further in $\mathrm{AD}$ diagnosis.

Paraconsistent Artificial Neural Networks - PANN is a new artificial neural network that will be presented briefly below.

The atomic formulas of the logic $E \tau$ are of the type $p_{(\mu, \lambda)}$, where $(\mu, \lambda) \in[0,1]^{2}$ and $[0,1]$ is the real unitary interval ( $p$ denotes a propositional variable). $p_{(\mu, \lambda)}$ can be intuitively read: "It is assumed that p's favorable evidence is $\mu$ and contrary evidence is $\lambda$." Thus,

- $p_{(1.0,0.0)}$ can be read as a true proposition.

- $p_{(0.0,1.0)}$ can be read as a false proposition.

- $p_{(1.0,1.0)}$ can be read as an inconsistent proposition.

- $P_{(0.0,0.0)}$ can be read as a paracomplete (unknown) proposition.

- $\quad p_{(0.5,0.5)}$ can be read as an indefinite proposition.

We introduce the following concepts (all considerations are made with $0 \leq \mu, \lambda \leq 1)$ : Uncertainty Degree: $G_{u n}(\mu, \lambda)$ $=\mu+\lambda-1$; Certainty Degree: $\mathrm{G}_{\mathrm{ce}}(\mu, \lambda)=\mu-\lambda$; an order relation is defined on $[0,1]^{2}:\left(\mu_{1}, \lambda_{1}\right) \leq\left(\mu_{2}, \lambda_{2}\right) \Leftrightarrow \mu_{1} \leq \mu_{2}$ and $\lambda_{1} \leq \lambda_{2}$, constituting a lattice that will be symbolized by $\tau$.

With the uncertainty and certainty degrees we can achieve the following 12 output states: extreme states that are, False, True, Inconsistent and Paracomplete, and nonextreme states.

Some additional control values are:

- $\mathrm{V}_{\mathrm{cic}}=$ maximum value of uncertainty control $=\mathrm{Ft}_{\mathrm{ct}}$

- $\mathrm{V}_{\mathrm{cve}}=$ maximum value of certainty control $=\mathrm{Ft}_{\mathrm{ce}}$

- $\mathrm{V}_{\mathrm{cpa}}=$ minimum value of uncertainty control $=-\mathrm{Ft}_{\mathrm{ct}}$

- $\mathrm{V}_{\mathrm{cfa}}=$ minimum value of certainty control $=-\mathrm{Ft}_{\mathrm{ce}}$

For the discussion in the present paper we have used: $\mathrm{Ft}_{\mathrm{ct}}=\mathrm{Ft}_{\mathrm{ce}}=1 / 2$. 
Table 1. Extreme and non-extreme states.

\begin{tabular}{lcll}
\hline Extreme states & Symbol & Non-extreme states & Symbol \\
\hline True & $\mathrm{V}$ & Quasi-true tending to Inconsistent & $\mathrm{QV} \rightarrow \mathrm{T}$ \\
False & $\mathrm{F}$ & Quasi-true tending to Paracomplete & $\mathrm{QV} \rightarrow \perp$ \\
Inconsistent & $\mathrm{T}$ & Quasi-false tending to Inconsistent & $\mathrm{QF} \rightarrow \mathrm{T}$ \\
Paracomplete & $\perp$ & Quasi-false tending to Paracomplete & $\mathrm{QF} \rightarrow \perp$ \\
& & Quasi-inconsistent tending to True & $\mathrm{QT} \rightarrow \mathrm{V}$ \\
& & Quasi-inconsistent tending to False & $\mathrm{QT} \rightarrow \mathrm{F}$ \\
& & Quasi-paracomplete tending to True & $\mathrm{Q} \perp \rightarrow \mathrm{V}$ \\
& & Quasi-paracomplete tending to False & $\mathrm{Q} \perp \rightarrow \mathrm{F}$ \\
\hline
\end{tabular}

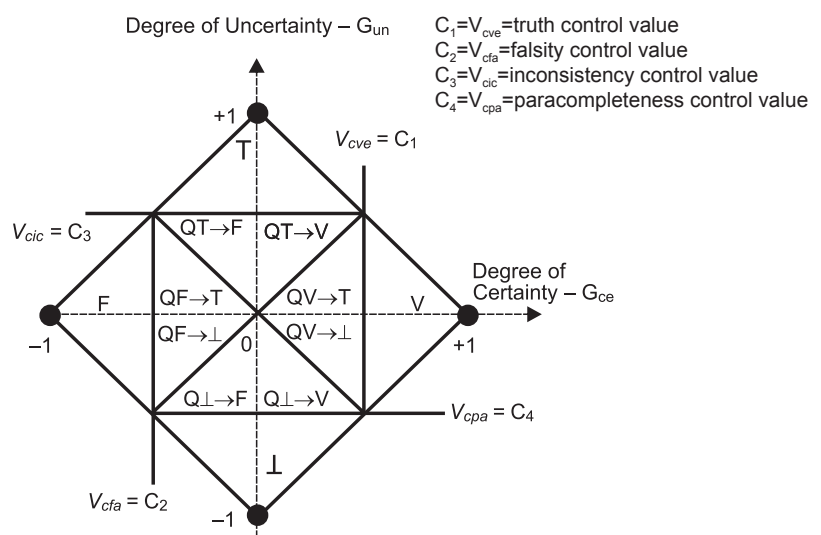

Figure 1. The figure displays the output regions of the lattice, constituting the decision-making of the inputs. In this lattice we have 12 output states: extreme and non-extreme states. See Table 1 for symbology.

All states are represented in Figure 1.

In the PANN the main aim is to ascertain how to determine the certainty degree concerning a proposition, i.e. if it is False or True. To this end, we take into account the certainty degree $G_{\text {ce }}$. The uncertainty degree $G_{\text {un }}$ indicates the 'measure' of the inconsistency or paracompleteness. If the certainty degree is low or the uncertainty degree is high, it generates an indefinition.

Using the concepts of basic Paraconsistent Artificial Neural Cell - PANC, we can obtain the family of PANC considered in this work, as described in Table 2.

\section{Methods}

We analyzed 10 controls and 10 AD EEGs records, during the awake state at rest, with subjects closing their eyes. We used electrodes placed according to the 10-20 international system, a 32 EEG channel EMSA device, with $200 \mathrm{~Hz}$ sample frequency.

The process of wave analysis by PANN consists previously of:

- Data capturing

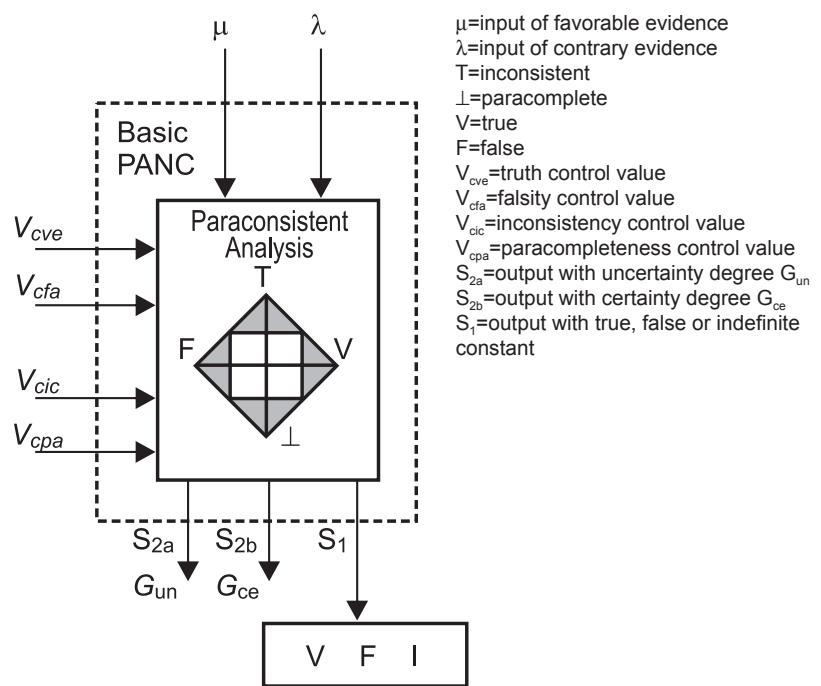

Figure 2. Basic cell of PANN.

The resulting certainty degree $G_{c e}$ is obtained as follows:

If: $V_{c f a} \leq G_{u n} \leq V_{c v e}$ or $V_{c i c} \leq G_{u n} \leq V_{c p a} \Rightarrow G_{c e}=$ Indefinition

For: $V_{c p a} \leq G_{u n} \leq V_{c i c}$

If: $G_{u n} \leq V_{c f a} \Rightarrow G_{c e}=$ False with degree $G_{u n}$

$V_{c i c} \leq G_{u n} \Rightarrow G_{c e}=$ True with degree $G_{u n}$

A Paraconsistent Artificial Neural Cell - PANC - is called basic PANC when a given pair $(\mu, \lambda)$ is used as input, and resulting as output: $G_{u n}=$ resulting uncertainty degree, $G_{c e}=$ resulting certainty degree, and $X=$ constant of Indefinition.

- Adaptation of the values for screen examination

- Elimination of the negative cycle

- Normalization of the values for PANN analysis

It is worth observing that the process above does not allow the loss of any essential wave characteristics for our analysis.

The capturing of the data is obtained from magnetic files (suitable software for physical capture of the signals) or manually (TXT files - American National Standard Code for Information Interchange).

As the actual EEG examination values can vary highly, 
Table 2. Paraconsistent artificial neural cells.

\begin{tabular}{|c|c|c|c|}
\hline PANC & Inputs & Calculations & Output \\
\hline Analytic connection $-\mathrm{PANC}_{\mathrm{ac}}$ & $\mu, \lambda, \mathrm{Ft}_{\mathrm{c},}, \mathrm{Ft}_{\mathrm{ce}}$ & $\lambda \mathrm{c}=1-\lambda, \mathrm{G}_{\mathrm{un}}, \mathrm{G}_{\mathrm{ce}}, \mu \mathrm{r}=\left(\mathrm{G}_{\mathrm{ce}}+1\right) / 2$ & $\begin{array}{l}\text { If }\left|G_{\mathrm{ce}}\right|>\mathrm{Ft}_{\mathrm{ce}} \text { then } S_{1}=\mu_{\mathrm{r}} \text { and } S_{2}=0 \text {; } \\
\text { If }\left|\mathrm{G}_{\mathrm{un}}\right|>\mathrm{Ft}_{\mathrm{ct}} \text { and }\left|\mathrm{G}_{\mathrm{un}}\right|>\left|\mathrm{G}_{\mathrm{ce}}\right| \text { then } \\
S_{1}=\mu_{\mathrm{r}} \text { and } S_{2}=\left|\mathrm{G}_{\mathrm{un}}\right| \text {, if not } S_{1}=1 / 2 \\
\text { and } S_{2}=0\end{array}$ \\
\hline Maximization - $\mathrm{PANC}_{\max }$ & $\mu, \lambda$ & none & If $\mu>\lambda$, then $S_{1}=\mu$, if not $S_{1}=\lambda$ \\
\hline Minimization $-\mathrm{PANC}_{\min }$ & $\mu, \lambda$ & none & If $\mu<\lambda$, then $S_{1}=\mu$, if not $S_{1}=\lambda$ \\
\hline
\end{tabular}

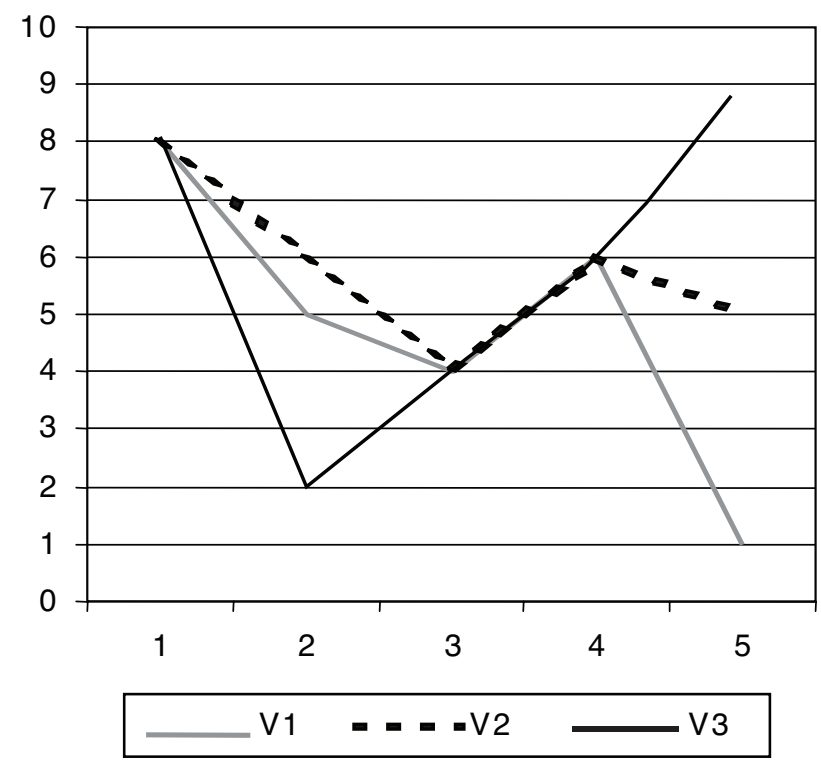

Figure 3. Comparison of the vectors. Taking as basis the vector $V_{1}$, visually we can observe that vector $V_{2}$ is 'more similar' to $V_{1}$ than $V_{3}$. We use a PANN to recognize this technical system.

in a module, somewhere between $10 \mu \mathrm{V}$ to $1500 \mu \mathrm{V}$, we proceed with normalization of the values to between $100 \mu \mathrm{V}$ and $-100 \mu \mathrm{V}$ by a simple linear conversion, to facilitate the processing and to visualize on the screen:

$$
x=\frac{100 . \mathrm{a}}{\mathrm{m}}
$$

where $m$ is the maximum value of the exam; $a$ is the current value of the exam. Therefore, $x$ is the current normalized value.

\section{Elimination of the negative cycle}

The minimum value of the exam is taken as a zero value and the remaining values are translated proportionally.

\section{Data analysis, expert system, and wave morphology}

In analyzing EEG signals, one important aspect to take into account is the morphological aspect. To perform this task, it is valuable to build one very simple Expert System, which allows "abnormalities" to be verified, such as spikes and artifacts. Also, it analyses the signal behavior, verifying which band it belongs to (delta, theta, alpha and beta).

\section{Morphological analysis}

The process of the morphological analysis of a wave is performed by comparing with a certain set of wave patterns (considered normal). A wave is associated to a vector (finite sequence of natural numbers $x_{\mathrm{i}}$ ) through digital sampling. This vector characterizes a wave pattern and is registered by the PANN. Thus, new waves are compared, allowing their recognition or otherwise. For the sake of completeness, we show some basic aspects of how PANN operates. Let us take three vectors: $\mathrm{V}_{1}=(8,5,4,6,1) ; \mathrm{V}_{2}=(8,6,4,6,5) ; \mathrm{V}_{3}=(8$, $2,4,6,9)$. The favorable evidence is calculated as follows: given a pair of vectors, we take ' 1 ' for equal elements and ' 0 ' for different elements, and calculate their percentage.

- Comparing $\mathrm{V}_{2}$ with $\mathrm{V}_{1}: 1+0+1+1+0=3$; in percentage: $(3 / 5)^{\star} 100=60 \%$.

- Comparing $\mathrm{V}_{3}$ with $\mathrm{V}_{1}: 1+0+1+1+0=3$; in percentage: $(3 / 5)^{*} 100=60 \%$.

The contrary evidence is the weighted addition of the differences between the different elements, in the module:

- Comparing $\mathrm{V}_{2}$ with $\mathrm{V}_{1}=0+1 / 10+0+0+4 / 10=(5 / 10) / 5$ $=10 \%$.

- Comparing $\mathrm{V}_{3}$ with $\mathrm{V}_{1}=0+3 / 10+0+0+8 / 10=(11 / 10) / 5$ $=22 \%$.

Therefore, we can state that $V_{2}$ is 'more similar' to $V_{1}$ than $V_{3}$. We use a PANN to recognize this system technique.

Also, the PANN is capable of adjusting its own recognizing factor and propagate to other layers, improving both 'proximity' level and 'recognizing' level, while also providing the approximate frequency of an analyzed wave.

For the purposes of this study, the favorable evidence was obtained by counting the wave peaks, i.e., the closer to the peak quantity, the greater the degree of favorable evidence:

$\mathrm{EF}=1-((\mathrm{lbd}-\mathrm{vtl}) /(\mathrm{bd}+\mathrm{vt}))$, where: 
- $\mathrm{Vt}=$ number of wave peaks of the exam

- $\mathrm{Bd}=$ number of the wave peaks being compared (pattern stored in the database)

Each peak is a $1 \mathrm{~Hz}$ morphological approximation; so a wave with 8 peaks is classified as $8 \mathrm{~Hz}$ wave (Alpha band).

\section{Data analysis}

Expert system for detecting the diminishing average frequency level - An expert system verifies the average frequency level of Alpha waves and compares them with a fixed external one (external parameter wave).

Such external parameter can be, for instance, the average frequency of a population or the average frequency of the last exam of the patient. This system also generates two outputs: favorable evidence $\mu$ (normalized values ranging from 0 (corresponds to $100 \%$ - or greater frequency loss) to 1 (which corresponds to $0 \%$ of frequency loss) and contrary evidence $\lambda(=1-\mu)$.

The population pattern used in this work is $10 \mathrm{~Hz}(6)$.

Expert system for Alpha band concentration - This expert system is utilized for Alpha band concentration in the exam. For this, we consider the quotient of the sum of fast Alpha and Beta waves over slow Delta and Theta waves, i.e., $($ Alpha + Beta) / (Delta + Theta).

This expert system generates two outputs:

- Favorable evidence $\mu$ : fast waves / (fast waves + slow waves).

- Contrary evidence: $\lambda=1-\mu$.

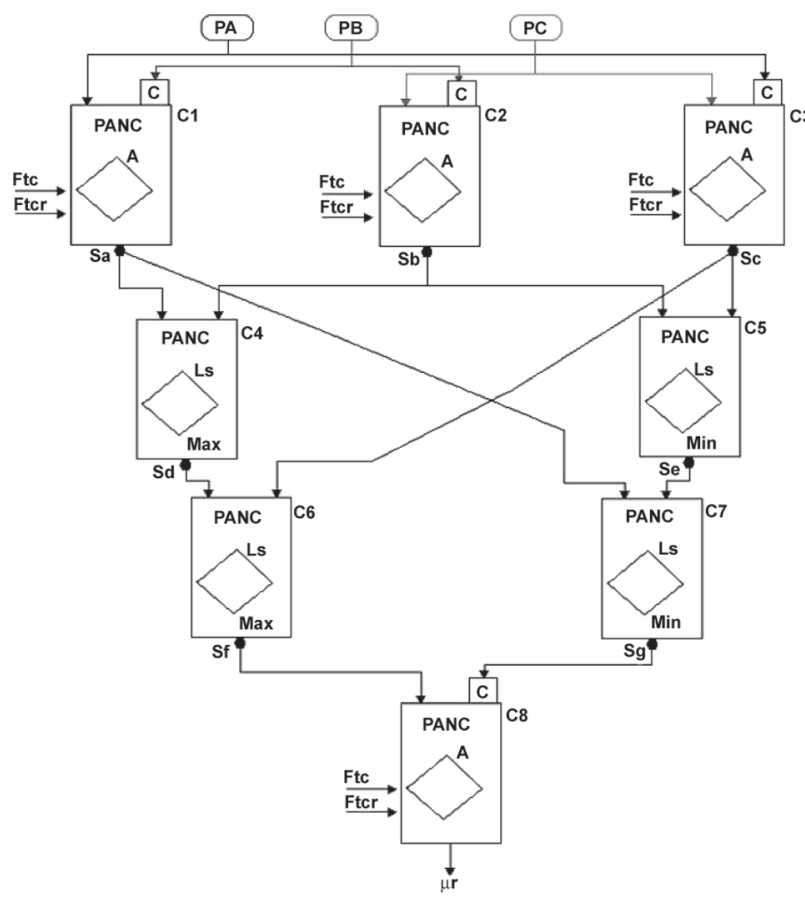

Expert system for Theta band concentration - This expert system is utilized for Delta band concentration in the exam. We consider (slow waves Delta + slow waves Theta) I (fast waves Alpha + fast waves Beta).

This expert system generates two outputs:

- Favorable evidence $\mu$ : 1-((slow waves) / (fast waves + slow waves)).

- Contrary evidence: $\lambda=1-\mu$.

\section{Data analysis}

When analyzing information from sources, we may encounter contradictory, fuzzy or paracomplete data. However, a decision can still be reached. For this, suppose that we have three items of information PA, PB, and PC, where $\mathrm{PA}$ and $\mathrm{PB}$ are being analyzed. If we cannot decide with this expert information, we take into account the third PC in the following way.

The first layer is composed of three analytical PANC connections: $\mathrm{C} 1, \mathrm{C} 2$, and $\mathrm{C} 3$ whose signals are analyzed by means of the Basic Structural Equation: BSE: $S=(\mu-(1-\lambda)$ $+1) / 2$ resulting in the output signals $S A, S B$, and SC.

In the internal layers, the cells $\mathrm{C} 4$ and $\mathrm{C} 6$ constitute the Maximization Neural Unit (it takes the maximum value SG among output values SA, SB, and SC) and the cells C5 and C7, the Minimization Neural Unit (which takes the minimum value SE among output values SA, SB, and SC).

Another way to define the interpretation of the analysis is to use the resultant value $\left(\mu_{\mathrm{r}}\right)$ and complements it; this generates a complemented resultant value $\left(\lambda_{\mathrm{r}}\right)$. In this

$\begin{array}{ll}\begin{array}{ll}\text { PANC A = Paraconsistent artificial neural } \\ \text { cell of analytic connection }\end{array} & \text { Ftcr = Contradiction tolerance factor } \\ & \mathrm{Sa}=\text { Output of C1 cell } \\ \begin{array}{l}\text { PANC Ls Max = Paraconsistent artificial } \\ \text { neural cell of simple logic connection of }\end{array} & \mathrm{Sb}=\text { Output of C2 cell } \\ \text { maximization } & \mathrm{Sc}=\text { Output of C3 cell } \\ \text { PANC Ls Min = Paraconsistent artificial } & \mathrm{Se}=\text { Output of C5 cell } \\ \text { neural cell of simple logic connection of } & \mathrm{Sf}=\text { Output of C6 cell } \\ \text { minimization } & \mathrm{Sg}=\text { Output of C7 cell } \\ \text { Ftc = Certainty tolerance factor } & \mathrm{C}=\text { Complemented value of input } \\ & \mu \mathrm{r}=\text { Value of output of PANN }\end{array}$

Figure 4. A decision-making architecture for global analysis. Three expert systems operate: $P A$, for detecting the diminishing average frequency level; $P B$, for Alpha band concentration, and PC, for Theta band concentration.

$C_{1}-P A N C$ which processes input data of $P A$ and $P B$

$C_{2}-P A N C$ which processes input data of $P B$ and $P C$

$C_{3}-P A N C$ which processes input data of $P C$ and $P A$

$C_{1}, C_{2}$, and $C_{3}$ constitute the $1^{\text {st }}$ layer of the architecture

$C_{4}-P A N C$ which calculates the maximum evidence value between cells $C_{1}$ and $C_{2}$ $C_{5}-P A N C$ which calculates the minimum evidence value between cells $C_{2}$ and $C_{3}$ $C_{4}$ and $C_{5}$ constitute the $2^{\text {nd }}$ layer of the architecture

$C_{6}-P A N C$ which calculates the maximum evidence value between cells $C_{4}$ and $C_{3}$ $C_{7}-P A N C$ which calculates the minimum evidence value between cells $C_{1}$ and $C_{5}$ $C_{6}$ and $C_{7}$ constitute the $3^{\text {rd }}$ layer of the architecture

$C_{8}$ analyzes the experts $P A, P B$, and $P C$ and gives the resulting decision value 
Table 3. Test with normal patients.

\begin{tabular}{cccccc}
\hline Casuistic & Patient & FE & CE & Mean & Diagnosis \\
\hline 7601 & JS & 0.4813 & 0.1404 & 6.9184 & 1 \\
7701 & RKG & 0.4813 & 0.0712 & 8.475 & 2 \\
5401 & EC & 0.4959 & 0.1377 & 7.025 & 2 \\
7801 & JIS & 0.5191 & 0.0603 & 8.5 & 1 \\
6501 & LANG & 0.5207 & 0.0548 & 8.425 & 1 \\
7101 & JTBT & 0.5419 & 0.0594 & 8.6 & 1 \\
7201 & OTWNV & 0.5896 & 0.0301 & 8.4 & 1 \\
1202 & RA & 0.8162 & 0.0613 & 10.2 & 1 \\
2102 & DYT & 0.8546 & 0.0485 & 18.825 & 1 \\
1802 & DO & 0.8818 & 0.0394 & 10.15 & 1 \\
\hline
\end{tabular}

$\mathrm{FE}$, favorable evidence; $\mathrm{CE}$, contrary evidence; 1 , normal patient; 2, probable $\mathrm{AD}$ patient.

Table 5. Diagnosis - Normal x Probable AD patients.

\begin{tabular}{lccc}
\hline & \multicolumn{3}{c}{ Gold Standard } \\
\cline { 2 - 4 } & AD patient & Non AD patient & Total \\
\hline Negative & 2 & 2 & 4 \\
Positive & 8 & 8 & 16 \\
Total & 10 & 10 & 20 \\
& \multicolumn{3}{|c}{ Gold Standard } \\
\cline { 2 - 4 } & AD patient & Non AD patient & Total \\
\hline Negative & $10.00 \%$ & $10.00 \%$ & $20.00 \%$ \\
Positive & $40.00 \%$ & $40.00 \%$ & $80.00 \%$ \\
Total & $50.00 \%$ & $50.00 \%$ & $100.00 \%$ \\
Sensitivity & 0.8 & \\
Specificity & 0.8 &
\end{tabular}

Table 4. Test with non-normal patients.

\begin{tabular}{cccccc}
\hline Casuistic & Patient & FE & CE & Mean & Diagnosis \\
\hline 4101 & MTRS & 0.3311 & 0.0596 & 7.55 & 2 \\
6001 & EGT & 0.4373 & 0.2072 & 5.921 & 2 \\
7901 & AMNT & 0.6851 & 0.0800 & 9.625 & 1 \\
5701 & ABC & 0.7398 & 0.0584 & 9.575 & 2 \\
2203 & JPNF & 0.1204 & 0.1185 & 6.175 & 2 \\
6201 & ESE & 0.1623 & 0.1159 & 7.55 & 2 \\
6301 & MF & 0.1865 & 0.1028 & 7.475 & 2 \\
7301 & AOFFS & 0.2332 & 0.0856 & 7.45 & 1 \\
5501 & TMOG & 0.2352 & 0.1551 & 6.15 & 2 \\
6401 & RRS & 0.2564 & 0.1721 & 6.3 & 2 \\
\hline
\end{tabular}

FE, favorable evidence; $\mathrm{CE}$, contrary evidence; 1 , normal patient; 2 , probable $\mathrm{AD}$ patient.

manner, we acquire resultant favorable evidence $\left(\mu_{\mathrm{r}}\right)$ and resultant contrary evidence $(\lambda r)$, as exemplified below:

We applied this methodology in two subjects (blind study), one of them normal and the other with $\mathrm{AD}$, and the method was able to distinguish both, classifying the normal subject in the normal standard of waves and the $\mathrm{AD}$ subject under the abnormal model.

\section{Results}

The proposed method was tested on 10 EEGs and the system correctly classified normal subjects at a rate of $80 \%$ with $20 \%$ as false-positive (Table 3 ).

In the following study, a further 10 EEGs were tested and the system correctly classified $\mathrm{AD}$ cases at a rate of $80 \%$ with $20 \%$ false-negative, as shown in Table 4.

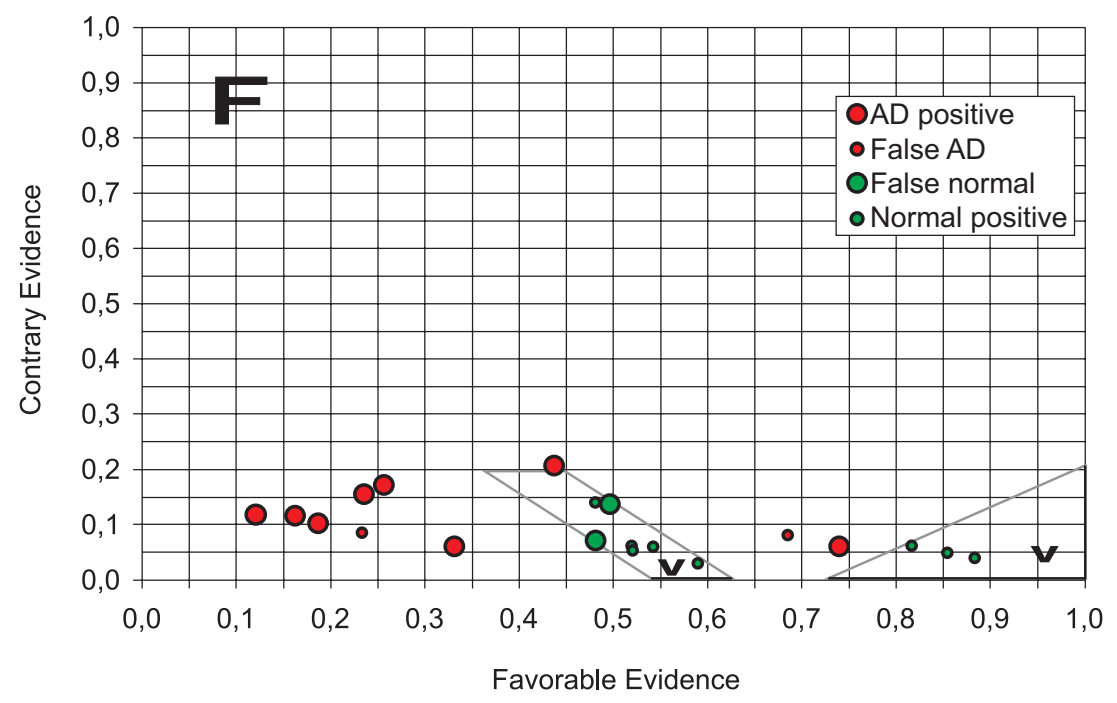

Figure 5. Final lattice of diagnosis decision states - Normal x Probable AD patients. We can observe two groups of normality: those non AD patients with Alpha concentration higher or equal to the average rate population (triangle of right side) and remaning non AD patients with Alpha concentration lower than average population rate. $F$, false output state; V, true output state. 


\section{Discussion}

For this preliminary test the normal pattern of a patient was considered as waves from $8 \mathrm{~Hz}$ to $12 \mathrm{~Hz}$, allowing a variance of $0.5 \mathrm{~Hz}$, thus representing the Alpha band. We stored 9 positive cycle wave patterns plus 9 negative cycle wave patterns. In this test periods were selected containing characteristics of the Alpha band, totaling 10 seconds. The PANN was capable of recognizing waves belonging to the Alpha band with favorable evidence of 0.30 and contrary evidence of 0.19 , while for waves not belonging to the Alpha pattern, an average favorable evidence of 0.19 and contrary evidence of 0.32 was achieved, demonstrating that PANN was efficient in recognizing Alpha waves.

The lattice in Figure 5 depicts two true state regions. This can be indicative of the existence of two groups of normality: non AD patients with Alpha concentration higher or equal to the average population rate (triangle to right side) and the remaining subjects which are non $\mathrm{AD}$ patients with Alpha concentration lower than the average population rate. The same observation seems applicable to the probable $\mathrm{AD}$ patients. A more complete study is currently underway the results of which are set to appear in forthcoming papers.

Acknowledgements - The authors are grateful to the anonymous referees who provided useful comments to improve the final version of the paper.

\section{References}

1. Duffy FH, Albert MS, Mcnulty G, Garvey AJ. Age differences in brain electrical activity of healthy subjects. Ann Neural 1984;16:430-438.

2. Nuwer MR, Comi G, Emerson R, et al. IFCN standards for digital recording of clinical EEG. Electroencephalogr Clin Neurophysiol 1998;106:259-261.

3. Nitrini R, Caramelli P, Bottino CM, Damasceno BP, Brucki SM, Anghinah R. Academia Brasileira de Neurologia. Diagnosis of Alzheimer's disease in Brazil: diagnostic criteria and au- xiliary tests. Recommendations of the Scientific Department of Cognitive Neurology and Aging of the Brazilian Academy of Neurology. Arq Neuropsiquiatr 2005;63:713-719.

4. Montenegro MA, Cendes F, Guerreiro MM, Guerreiro CAM, editors. EEG na Prática Clínica, São Paulo: Lemos Editorial; 2001.

5. Abe JM. Fundamentos da lógica anotada. Thesis, Faculdade Filosofia Letras e Ciências Humanas da Universidade de São Paulo, São Paulo, Brazil, 1992.

6. Anghinah R. Estudo da densidade espectral e da coerência do eletrencefalograma em indivíduos adultos normais e com doença de Alzheimer provável. Thesis, Faculdade de Medicina da Universidade de São Paulo, São Paulo, Brazil, 2003.

7. Da Costa NCA, Abe JM, Silva Filho JI, Murolo AC, Leite CFS. Lógica Paraconsistente Aplicada. São Paulo: Editora Atlas; 1999.

8. Da Silva Filho JI, Abe JM. Fundamentos das redes neurais paraconsistentes: destacando aplicações em neurocomputação. São Paulo: Editora Arte \& Ciência; 2001.

9. Erganian A, Mahmoudi B. Real-time ocular artifact suppression using recurrent neural network for electro-encephalogram based brain-computer interface. Med Biol Eng Comput 2005;43:296-305.

10. Fausett L. Fundamentals of neural network architectures, algorithms, and applications, US Ed edition, New York: Prentice Hall, 1994.

11. Subasi A, Alkan A, Koklukaya E, Kiymik MK. Wavelet neural network classification of EEG signals by using AR model with MLE preprocessing, Neural Netw 2005;18:985-997.

12. Ventouras EM, Monoyou EA, Ktonas PY, et al. 25 Sleep spindle detection using artificial neural networks trained with filtered time-domain EEG: a feasibility study. Comput Methods Programs Biomed 2005;78:191-207.

13. Miller A. The application of neural networks to imaging and signal processing in astronomy and medicine. Thesis, Faculty of Science, Department of Physics, University of Southampton, 1993.

14. Weinstein J, Kohn K, Grever M. Neural computing in cancer drug development: predicting mechanism of action. Science 1992;258:447-451.

15. Baxt WJ. Application of artificial neural network to clinical medicine. Lancet 1995;346:1135-1138. 